\title{
The Effect of Sleep Duration on the Risk of Unintentional Injury in Korean Adults
}

\author{
Yeon-Yong Kim ${ }^{1}$, Un-Na Kim ${ }^{1}$, Jin-Seok Lee ${ }^{1,2}$, Jong-Heon Park ${ }^{2}$ \\ ${ }^{1}$ Department of Health Policy and Management, Seoul National University College of Medicine, Seoul; Institute of Health Policy and Management, \\ Medical Research Center, Seoul National University, Seoul, Korea
}

Objectives: The decrease or increase in sleep duration has recently been recognized as a risk factor for several diseases, including hypertension and obesity. Many studies have explored the relationship of decreased sleep durations and injuries, but few have examined the relationship between increased sleep duration and injury. The objective of this research is to identify the risk for injury associated with both decreased and increased sleep durations.

Methods: Data from the 2010 Community Health Survey were used in this study. We conducted logistic regression with average sleep duration as the independent variable, injury as a dependent variable, and controlling for age, sex, occupation, education, region (cities and provinces), smoking, alcohol use, body mass index, hypertension, diabetes, arthritis, and depression. Seven categories of sleep duration were established: $\leq 4,5,6,7,8,9$, and $\geq 10$ hours.

Results: Using 7 hours of sleep as the reference, the adjusted injury risk (odds ratio) for those sleeping a total of $\leq 4 \mathrm{~h} / \mathrm{d}$ was $1.53 ; 1.28$ for 5 hours, for 1.11 for 6 hours, 0.98 for 8 hours, 1.12 for 9 hours, and 1.48 for $\geq 10$ hours. The difference in risk was statistically significant for each category except for the 8 and 9 hours. In this study, risk increased as the sleep duration decreased or increased, except for the 8 and 9 hours.

Conclusions: This research found that either a decrease or increase in sleep duration was associated with an increased risk for injury. The concept of proper sleep duration can be evaluated by its associated injury risk.

Key words: Sleep duration, Wounds and injuries, Community health survey

\section{INTRODUCTION}

Approximately $20 \%$ of the adult population experiences periods of decreased sleep duration [1]. In industrialized societ-

Received: October 16, 2013; Accepted: April 25, 2014

Corresponding author: Jong-Heon Park, MD, PhD

311 Dongmak-ro, Mapo-gu, Seoul 121-749, Korea

Tel: +82-2-3270-9699, Fax: +82-2-3275-8024

E-mail: parkjh@nhis.or.kr

This is an Open Access article distributed under the terms of the Creative Commons Attribution Non-Commercial License (http://creativecommons.org/licenses/by$\mathrm{nc} / 3.0 /$ ) which permits unrestricted non-commercial use, distribution, and reproduction in any medium, provided the original work is properly cited. ies, sleep duration has consistently been decreasing due to increases in work hours and available leisure time activities [2,3]. According to a 2009 study by the Organisation for Economic Cooperation and Development, the mean sleep duration of Koreans was 7 hours and 49 minutes, which was the lowest of all 18 nations [4], yet the effect of sleep duration on health is not receiving much attention.

A decrease in sleep duration can manifest in mental illnesses, such as bipolar disorder and depressive disorder. However, it is also known to affect morbidity and mortality and is related to physical illness. Studies abroad have investigated the association between decreased sleep duration and hypertension [5], diabetes mellitus [6], coronary artery disease [7], and obe- 
sity [8], while domestic studies have been conducted on hypertension [9] and obesity [10,11]. A number of studies have shown a direct association between decreased sleep duration and physical illness $[5,10,11]$; sleep duration exceeding 7 to 8 hours has also been found to have an impact on physical illness [6-9]. Accordingly, recent studies are examining not only the impact on health of a decrease or increase in sleep duration $[12,13]$ but also searching for a definition of "optimal sleep duration" [14]. However, the empirical evidence establishing optimal sleep duration is insufficient. The interest in sleep duration is growing, and studies on long sleep durations as a health risk factor or a symptom [15] have been conducted. There have been studies focusing on long sleepers [16] and the effects of sleep duration on cognitive function and physical health $[17,18]$. The biological mechanisms of sleep, which have yet to be identified, are also being studied. Existing studies have shown how sleep deprivation can lead to accidents and impaired cognitive function, including a study on effects of sleep deprivation on attention and working memory in medical residents [19].

Impaired cognitive function can lead to injury. Unintentional injury occurs without any internal or external intent and includes traffic accidents, poisoning, falls, fires and burns, and drowning. In Korea, the significance of traffic accident looms large, as it is one of the top three causes of death in each age group under 40 [20]. Injuries tend to appear in younger age groups, leading to significant economic losses, including the loss of productivity. In Korea, a study was conducted on the association between sleep duration and traffic accident rates among taxi drivers [21]. In the US, Lombardi et al. [22] and Lombardi et al. [23] conducted studies on sleep duration and work-related injuries using the vast data from the US National Health Interview Survey. Previous studies have found that insufficient sleep increases the risk for injury. However, one domestic study focused on only one specific occupation, and the US study did not find a clear relationship between increases of sleep and injury.

The purpose of this study was to investigate the effect of sleep duration on the risk of unintentional injury in Korean adults and using the findings to add to the discussion of optimal sleep duration. To overcome the limitations of previous studies, this study used data from the nationwide representative Community Health Survey.

\section{METHODS}

\section{Subjects}

This study analyzed the data from the Community Health Survey, which was conducted in 2010 by the Korea Centers for Disease Control and Prevention under the Korean Ministry of Health and Welfare. The 2010 Community Health Survey was a survey conducted at 253 public health centers, with an average of 900 people per location. The subjects were adults from selected households who were older than 19 years (born prior to July 31,1994$)$, excluding non-naturalized foreigners, unrelated household members, and military personnel not living at a permanent address. The survey was conducted using a computer assisted personal interviewing method, that is, the surveyors visited the survey sites with electronic questionnaires on a laptop. Of the 229229 questionnaires completed by the selected individuals, questionnaires with missing data, answers \pm 3 standard deviations (SD) from the mean or other outliers, and intentional injuries were excluded, yielding data from 213274 individuals for analysis. For intentional injuries, the intent was described as either "intentional self-harm" or "assault by others" at the survey. No answer and "I don't know" responses were treated as missing data.

\section{Variable Definitions \\ Independent and dependent variables}

For this research, the variable sleep duration was the number of hours slept determined by the question, "How many hours do you typically sleep a day?" The answers were placed in seven sleep duration categories: $\leq 4,5,6,7,8,9$, and $\geq 10$ hours. For injuries, those who answered "yes" to having treatments at a medical facility or emergency room due to unintentional injuries or poisoning (food poisoning was excluded) were defined as the "injury" and those who answered "no" were defined as the "non-injury".

\section{Control variables}

For current smoking status, those who had smoked more than 5 packs (100 cigarettes) and answered that they still smoke were identified as the "current smoking group" and the rest were identified as the "non-smoking group." The 2010 Community Health Survey used the Alcohol Use Disorder Identification Test (AUDIT), which was developed by the World Health Organization to measure alcohol dependence and problem drinking. Categories for the AUDIT study were based 
on research by Kim et al. [24]: 0 to 11 points, "normal drinking"; 12 to 14 points, "problem drinking"; 15 to 25 points, "alcohol abuse"; and 26 to 40 points, "alcohol dependence." Those who had never had a single serving of alcohol or did not have any alcohol in the past year were defined as the "non-drinking group."

Body mass index $\left(\mathrm{BMl}, \mathrm{kg} / \mathrm{m}^{2}\right)$ was calculated by dividing weight $(\mathrm{kg})$ by the square of height $(\mathrm{m})$; groups with BMI of below $18.5 \mathrm{~kg} / \mathrm{m}^{2}$ were classified as the "underweight group," 18.5 to $23 \mathrm{~kg} / \mathrm{m}^{2}$ as the "normal weight group" 23 to $25 \mathrm{~kg} / \mathrm{m}^{2}$ as the "overweight group" and greater than $25 \mathrm{~kg} / \mathrm{m}^{2}$ as the "obesity group." For hypertension, diabetes mellitus, arthritis, or depression, those who had answered that they had been previously diagnosed by a doctor were defined as the "diagnosed group" and those who answered they had not been diagnosed were defined as the "nondiagnosed group."

General characteristics questions consisted of age, gender, occupation, education, and region. Age was broken into the following groups: "19 to 29, ,"'30 to 39 ,"' 40 to 49 ,,"'50 to 59 ,"'60 to 69 ," and " $\geq 70$." Based on the work of Kim et al. [25] and Jung et al. [26], occupations were defined as "low injury risk," "high injury risk" and an "other." The "low injury risk group" included managers, professionals and related workers, and clerks. The "high injury risk group" included agriculture, forestry, and fishery; craft and related trades; equipment, machine operation and assembling; elementary; service, sales, and armed forces. The "other group" included students, housewives, and the unemployed. For educational level, participants were classified as "uneducated and elementary school," "middle and high school," or "college or university." Seoul and other major cities were defined as "metropolitan area" and other areas were defined as "provincial area."

\section{Statistical Analyses}

Univariate analysis on injury was performed using chisquared test for variables that might influence the outcome. For each variable related to sleep duration, $t$-test and analyses of variance were performed. Multicollinearity was excluded and complex sample analysis was performed using stratification variables, cluster variables, and adjusted person-weight from the Community Health Survey. Person weight reflects personal questions from the household weight and is adjusted for gender and age, relative to registered residents; as part of the survey design, this allowed an individual subject to represent the entire population of the region. Logistic regression was performed using sleep duration as the independent variable, injury as the dependent variable, and other variables as control variables. The reference point for sleep duration was set at 7 hours, consistent with other studies $[6,10,22,23]$. The odds ratio was calculated with a $95 \%$ confidence interval. Control variables consisted of age, gender, occupation, educational level, region, current smoking status, alcohol usage, and $\mathrm{BMI}$, along with the diagnosis of hypertension, diabetes mellitus, arthritis, or depression. IBM SPSS version 21.0 (IBM Co., Armonk, NY, USA) was the statistics program used, with the significance level was set to 0.05 .

\section{RESULTS}

\section{Chi-squared Testing of Subject Characteristics and Injury Experience}

Descriptive analysis of participant characteristics was performed, as well as chi-squared tests for variables that may affect injuries (Table 1).

In terms participant characteristics, the 40 to 49 age group was the most common, and there were more females than males. For occupation, the highest number belonged to the high injury risk group, with the least belonging to low injury risk group. For educational level, the middle and high school group had the largest number of participants and the college or university group had the least. For region, there were more in the province group than in the metropolitan city group. There were more participants in the non-smoking group than in the current smoking group, and the normal drinking group was larger than the other AUDIT groups. The alcohol dependence group was the smallest. The largest number of participants was in the normal weight group, and the smallest number was in the underweight group. Hypertension, arthritis, diabetes mellitus, and depression were present in $21.1 \%, 13.1 \%$, $8.0 \%$, and $2.3 \%$ participants, respectively. Five percent the respondents had a history of injury. In the sleep duration categories, the 7 hours group had the most participants (32.5\%) and $\geq 10$ hours group had the least (2.0\%) percentage of participants.

The results of the chi-squared testing of individual variables with respect to injury showed that injury rate was lowest in the 30 to 39 age group and the rate increased with an increase or decrease in age relative to this age group, but these differences were not statistically significant. Men reported more injuries, and the high injury risk group had the most injury expe- 
Table 1. Sociodemographic and health-related characteristics of the study population

\begin{tabular}{|c|c|c|c|c|}
\hline \multicolumn{2}{|l|}{ Variables } & \multirow{2}{*}{$\begin{array}{c}\text { Total } \\
213274\end{array}$} & \multirow{2}{*}{$\begin{array}{c}\text { Injury (\% of in- } \\
\text { jury population) }\end{array}$} & \multirow[t]{2}{*}{$p$-value } \\
\hline Total & & & & \\
\hline \multirow[t]{6}{*}{ Age (y) } & $19-29$ & 26627 & $1285(4.8)$ & 0.16 \\
\hline & $30-39$ & 37784 & $1720(4.6)$ & \\
\hline & $40-49$ & 42901 & $2028(4.7)$ & \\
\hline & $50-59$ & 39621 & $1890(4.8)$ & \\
\hline & $60-69$ & 33407 & $1693(5.1)$ & \\
\hline & $\geq 70$ & 32934 & $1851(5.6)$ & \\
\hline \multirow[t]{2}{*}{ Gender } & Male & 97113 & $5090(5.2)$ & $<0.001$ \\
\hline & Female & 116161 & $5377(4.6)$ & \\
\hline \multirow[t]{3}{*}{ Occupation } & Low injury risk & 40044 & $1658(4.1)$ & $<0.001$ \\
\hline & High Injury risk & 88264 & $4670(5.3)$ & \\
\hline & Other & 84966 & $4139(4.9)$ & \\
\hline \multirow[t]{3}{*}{ Education } & $\begin{array}{l}\text { Uneducated and } \\
\text { elementary }\end{array}$ & 58998 & $3260(5.5)$ & $<0.001$ \\
\hline & Middle and high & 97418 & $4808(4.9)$ & \\
\hline & $\begin{array}{l}\text { College or } \\
\text { university }\end{array}$ & 56858 & $2399(4.2)$ & \\
\hline \multirow[t]{2}{*}{ Region } & Metropolitan area & 66264 & $3129(4.7)$ & 0.008 \\
\hline & Provincal area & 147010 & $7338(5.0)$ & \\
\hline \multirow[t]{2}{*}{ Smoking } & Non-smoker & 166213 & $7787(4.7)$ & $<0.001$ \\
\hline & Current smoker & 47061 & $2680(5.7)$ & \\
\hline \multirow[t]{5}{*}{ Alcohol } & Non-drinking & 76061 & $3583(4.7)$ & 0.012 \\
\hline & Normal drinking & 110333 & $5052(4.6)$ & \\
\hline & Problem drinking & 9617 & $543(5.6)$ & \\
\hline & Alcohol abuse & 15824 & $1129(7.1)$ & \\
\hline & $\begin{array}{l}\text { Alcohol } \\
\text { dependence }\end{array}$ & 1439 & $160(11.1)$ & \\
\hline \multirow{4}{*}{ Body mass index } & Underweight & 19458 & $1002(5.1)$ & 0.005 \\
\hline & Normal & 96400 & $4520(4.7)$ & \\
\hline & Overweight & 49336 & 2407 (4.9) & \\
\hline & Obesity & 48050 & $2538(5.3)$ & \\
\hline \multirow[t]{2}{*}{ Hypertension } & Yes & 44960 & $2457(5.5)$ & $<0.001$ \\
\hline & No & 168314 & $8010(4.8)$ & \\
\hline \multirow{2}{*}{$\begin{array}{l}\text { Diabetes } \\
\text { mellitus }\end{array}$} & Yes & 16969 & $1033(6.1)$ & $<0.001$ \\
\hline & No & 196305 & $9434(4.8)$ & \\
\hline \multirow[t]{2}{*}{ Arthritis } & Yes & 27837 & $1774(6.4)$ & $<0.001$ \\
\hline & No & 185437 & $8693(4.7)$ & \\
\hline \multirow[t]{2}{*}{ Depression } & Yes & 4918 & 422 (8.6) & $<0.001$ \\
\hline & No & 208356 & 10045 (4.8) & \\
\hline \multirow{7}{*}{ Sleep duration (h) } & $\leq 4$ & 7523 & $533(7.1)$ & $<0.001$ \\
\hline & 5 & 23314 & $1342(5.8)$ & \\
\hline & 6 & 59342 & $2955(5.0)$ & \\
\hline & 7 & 69290 & 3051 (4.4) & \\
\hline & 8 & 43902 & $1994(4.5)$ & \\
\hline & 9 & 5573 & 303 (5.4) & \\
\hline & $\geq 10$ & 4330 & 292 (6.7) & \\
\hline
\end{tabular}

riences among the occupation categories. In educational levels, the uneducated and elementary school group had highest rate of injury experiences and province group had more injury experiences than the metropolitan city group. The current smokers had a higher injury rate than non-smokers. The alcohol dependent group reported the highest injury rate of all the subgroups. In terms of BMI, the normal weight group had the lowest occurrence of injury experiences with rates increasing relative to any increase or decrease in weight. The diagnosed group had a higher injury rate than the undiagnosed group. Finally, any increase or decrease in sleep duration from the 7 hours reference had a U-shaped distribution of injury rates, showing an increase of injury occurrence as sleep duration increased or decreased.

\section{Mean Sleep Duration of Each Variable Subgroup Effecting Injury}

A $t$-test was conducted using the mean sleep duration time of each variable subgroup related to injury were performed (Table 2). The mean sleep duration for all subjects was 6.72 hours (SD, 1.24). The injury group had a lower sleep duration than the non-injury group. Age, gender (female), all occupations, educational levels, all regions, and portions of the smoking, drinking, BMI, hypertension, diabetes mellitus, arthritis, and the depression groups were statistically significant.

\section{Logistic Regression Analysis of Injury Causing Factors}

Multivariable logistic regression analysis was performed to control the variables related to injury except for sleep duration (Table 3). Using the 7 hours sleep group as reference, a decrease in sleep duration was significantly associated with an increase in injury, while an increase in sleep duration was also associated with an increase in injury, in all groups except the 8 and 9 hours groups (Figure 1). Among sleep duration groups, $\leq 4$ hours group had the highest risk of injury, and among control variables, the specific subgroups, alcohol abuse, alcohol dependence, and diagnosed depression had the highest risk of injury. Younger members of the 30 to 39 age group had a higher risk and those participants over 50 years of age had a lower risk of injuries. The high injury risk occupations had a higher injury risk that the low injury risk occupations. Compared to the college or university groups, the uneducated and elementary participants had a 1.26 times higher risk and a 1.13 higher risk was found for the middle and high school group. 
Table 2. T-tests between the injury-experienced group and injury non-experienced group for mean sleep duration time by subgroup

\begin{tabular}{|c|c|c|c|c|}
\hline \multirow{2}{*}{\multicolumn{2}{|c|}{ Variables }} & \multicolumn{2}{|c|}{$\begin{array}{l}\text { Sleep duration time } \\
\quad(\text { mean } \pm S D)\end{array}$} & \multirow[t]{2}{*}{$p$-value } \\
\hline & & Injury & Non-injury & \\
\hline \multicolumn{2}{|l|}{ Total } & $6.64 \pm 1.35$ & $6.72 \pm 1.23$ & $<0.001$ \\
\hline \multirow[t]{6}{*}{ Age (y) } & $19-29$ & $6.93 \pm 1.34$ & $6.97 \pm 1.19$ & 0.30 \\
\hline & $30-39$ & $6.75 \pm 1.17$ & $6.83 \pm 1.07$ & 0.007 \\
\hline & $40-49$ & $6.55 \pm 1.17$ & $6.67 \pm 1.07$ & $<0.001$ \\
\hline & $50-59$ & $6.51 \pm 1.25$ & $6.64 \pm 1.17$ & $<0.001$ \\
\hline & $60-69$ & $6.54 \pm 1.38$ & $6.61 \pm 1.32$ & 0.07 \\
\hline & $\geq 70$ & $6.67 \pm 1.67$ & $6.68 \pm 1.55$ & 0.68 \\
\hline \multirow[t]{2}{*}{ Gender } & Male & $6.70 \pm 1.30$ & $6.73 \pm 1.19$ & 0.11 \\
\hline & Female & $6.59 \pm 1.39$ & $6.71 \pm 1.27$ & $<0.001$ \\
\hline \multirow[t]{3}{*}{ Occupation } & Low injury risk & $6.58 \pm 1.10$ & $6.64 \pm 1.00$ & 0.02 \\
\hline & High Injury risk & $6.63 \pm 1.25$ & $6.67 \pm 1.16$ & 0.02 \\
\hline & Other & $6.68 \pm 1.53$ & $6.81 \pm 1.39$ & $<0.001$ \\
\hline \multirow[t]{3}{*}{ Education } & $\begin{array}{l}\text { Uneducated and } \\
\text { elementary }\end{array}$ & $6.60 \pm 1.52$ & $6.64 \pm 1.45$ & 0.11 \\
\hline & Middle and high & $6.68 \pm 1.30$ & $6.76 \pm 1.19$ & $<0.001$ \\
\hline & $\begin{array}{l}\text { College or } \\
\text { university }\end{array}$ & $6.62 \pm 1.16$ & $6.73 \pm 1.06$ & $<0.001$ \\
\hline \multirow[t]{2}{*}{ Region } & $\begin{array}{l}\text { Metropolitan } \\
\text { area }\end{array}$ & $6.59 \pm 1.32$ & $6.65 \pm 1.21$ & 0.005 \\
\hline & Provincal area & $6.67 \pm 1.35$ & $6.75 \pm 1.24$ & $<0.001$ \\
\hline \multirow[t]{2}{*}{ Smoking } & Non-smoker & $6.65 \pm 1.31$ & $6.70 \pm 1.20$ & 0.05 \\
\hline & Current smoker & $6.64 \pm 1.36$ & $6.73 \pm 1.24$ & $<0.001$ \\
\hline \multirow[t]{5}{*}{ Alcohol } & Non-drinking & $6.63 \pm 1.48$ & $6.71 \pm 1.35$ & 0.001 \\
\hline & Normal drinking & $6.66 \pm 1.25$ & $6.74 \pm 1.15$ & $<0.001$ \\
\hline & Problem drinking & $6.64 \pm 1.28$ & $6.68 \pm 1.15$ & 0.42 \\
\hline & Alcohol abuse & $6.61 \pm 1.30$ & $6.66 \pm 1.21$ & 0.27 \\
\hline & $\begin{array}{l}\text { Alcohol } \\
\text { dependence }\end{array}$ & $6.46 \pm 1.64$ & $6.56 \pm 1.49$ & 0.39 \\
\hline \multirow{4}{*}{$\begin{array}{l}\text { Body mass } \\
\text { index }\end{array}$} & Underweight & $6.70 \pm 1.58$ & $6.76 \pm 1.46$ & 0.22 \\
\hline & Normal & $6.70 \pm 1.34$ & $6.76 \pm 1.21$ & 0.002 \\
\hline & Overweight & $6.62 \pm 1.28$ & $6.68 \pm 1.18$ & 0.014 \\
\hline & Obesity & $6.55 \pm 1.30$ & $6.66 \pm 1.23$ & $<0.001$ \\
\hline \multirow[t]{2}{*}{ Hypertension } & Yes & $6.55 \pm 1.48$ & $6.62 \pm 1.38$ & 0.012 \\
\hline & No & $6.67 \pm 1.30$ & $6.75 \pm 1.19$ & $<0.001$ \\
\hline \multirow{2}{*}{$\begin{array}{l}\text { Diabetes } \\
\text { mellitus }\end{array}$} & Yes & $6.62 \pm 1.54$ & $6.73 \pm 1.44$ & 0.030 \\
\hline & No & $6.64 \pm 1.32$ & $6.72 \pm 1.22$ & $<0.001$ \\
\hline \multirow[t]{2}{*}{ Arthritis } & Yes & $6.45 \pm 1.50$ & $6.51 \pm 1.43$ & 0.09 \\
\hline & No & $6.68 \pm 1.31$ & $6.75 \pm 1.20$ & $<0.001$ \\
\hline \multirow[t]{2}{*}{ Depression } & Yes & $6.41 \pm 1.64$ & $6.48 \pm 1.70$ & 0.40 \\
\hline & No & $6.65 \pm 1.33$ & $6.73 \pm 1.22$ & $<0.001$ \\
\hline
\end{tabular}

Smokers were at a 1.14 times higher risk than non-smokers and, compared to non-drinkers, a higher risk was found for normal drinkers (1.08), problem drinkers (1.33), alcohol abus-
Table 3. Result of logistic regression analysis predicting injury risk, adjusting for significant covariates

\begin{tabular}{|c|c|c|}
\hline & & $\mathrm{aOR}^{1}(95 \% \mathrm{CI})$ \\
\hline \multicolumn{3}{|l|}{ Independent variable } \\
\hline \multirow{6}{*}{$\begin{array}{l}\text { Sleep duration (h) } \\
\text { (ref: 7) }\end{array}$} & $\leq 4$ & $1.527(1.343,1.735)$ \\
\hline & 5 & $1.281(1.177,1.394)$ \\
\hline & 6 & $1.111(1.040,1.187)$ \\
\hline & 8 & $0.982(0.909,1.061)$ \\
\hline & 9 & $1.120(0.947,1.324)$ \\
\hline & $\geq 10$ & $1.480(1.241,1.765)$ \\
\hline \multicolumn{3}{|l|}{ Control variables } \\
\hline \multirow{5}{*}{$\begin{array}{l}\text { Age (y) } \\
\text { (ref: 30-39) }\end{array}$} & $19-29$ & $1.103(1.008,1.207)$ \\
\hline & $40-49$ & $0.952(0.877,1.033)$ \\
\hline & $50-59$ & $0.907(0.829,0.992)$ \\
\hline & $60-69$ & $0.849(0.762,0.947)$ \\
\hline & $\geq 70$ & $0.877(0.774,0.993)$ \\
\hline Gender (ref: female) & Male & $1.006(0.943,1.075)$ \\
\hline \multirow[t]{2}{*}{ Occupation (ref: injury low risk) } & High injury risk & $1.202(1.111,1.299)$ \\
\hline & Other & $1.088(0.998,1.186)$ \\
\hline \multirow[t]{2}{*}{ Education (ref: college or university) } & $\begin{array}{l}\text { Uneducated and } \\
\text { elementary }\end{array}$ & $1.263(1.137,1.403)$ \\
\hline & Middle and high & $1.125(1.049,1.207)$ \\
\hline Region (ref: metropolitan area) & Provincal area & $1.034(0.980,1.090)$ \\
\hline Smoking (ref: non-smoker) & Current smoker & $1.139(1.063,1.220)$ \\
\hline \multirow[t]{4}{*}{ Alcohol (ref: non-drinking) } & Normal drinking & $1.081(1.015,1.152)$ \\
\hline & Problem drinking & $1.334(1.178,1.511)$ \\
\hline & Alcohol abuse & $1.572(1.422,1.738)$ \\
\hline & $\begin{array}{l}\text { Alcohol } \\
\text { dependence }\end{array}$ & $2.312(1.871,2.858)$ \\
\hline \multirow[t]{3}{*}{ Body mass index (ref: normal) } & Underweight & $1.057(0.955,1.169)$ \\
\hline & Overweight & $1.018(0.951,1.089)$ \\
\hline & Obesity & $1.037(0.969,1.110)$ \\
\hline Hypertension (ref: no) & Yes & $1.038(0.964,1.117)$ \\
\hline Diabetes mellitus (ref: no) & Yes & $1.135(1.032,1.247)$ \\
\hline Arthritis (ref: no) & Yes & $1.390(1.276,1.514)$ \\
\hline Depression (ref: no) & Yes & $1.708(1.499,1.946)$ \\
\hline
\end{tabular}

aOR, adjusted odds ratio; $\mathrm{Cl}$, confidence interval.

${ }^{1}$ Adjusted for all other variables in the table.

ers (1.57) and the alcohol dependent groups (2.31). Relative to the normal weight group, a higher risk was associated with being underweight (1.06), overweight (1.02), and obese (1.04), but none of these results were statistically significant. Those with diagnosed and undiagnosed hypertension groups had the same level of risk, but participants diagnosed with diabetes mellitus, arthritis, and depression had a higher risk of 1.14, 1.39 , and 1.71 , respectively, than the non-diagnosed group. There were no significant differences in gender or area. 


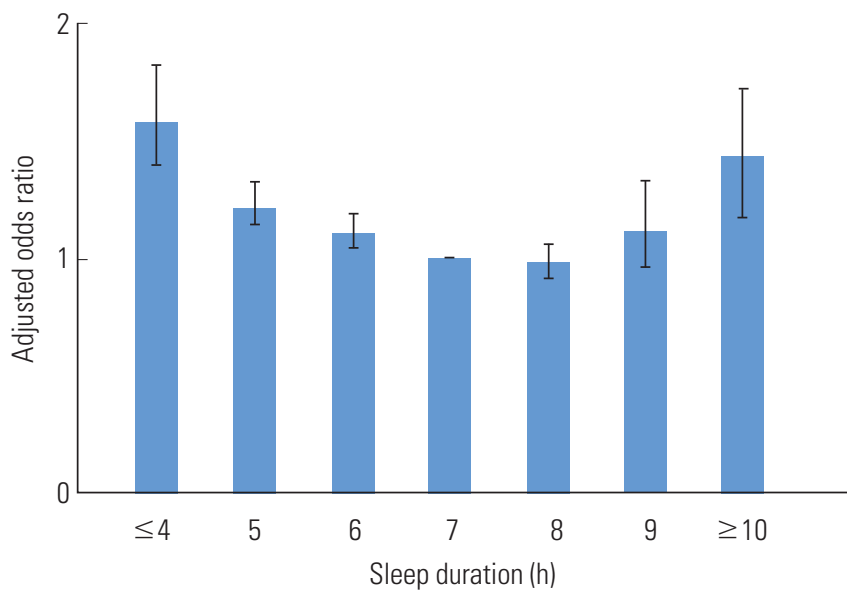

Figure 1. Injury risk (adjusted odds ratio) of sleep duration.

\section{DISCUSSION}

This study examined the effect of sleep duration on the risk of unintentional injury using the 2010 Community Health Survey data. Excluding the 8 and 9 hours sleep groups, sleep duration was associated with increased risk for injury in a Ushaped distribution relative to the 7 hours sleep group. This finding is similar to those from previous research on sleep duration and physical illness [6-9,12,13], where a decrease or increase in sleep duration had an effect on health. Sleep duration has been associated with a decrease in cognitive function; Kim et al. [19] found that as the severity of sleep deprivation increased, medical residents experienced higher levels of stress and struggled with drowsiness, affecting attention and academic performance. Youn et al. [21] reported that sleep deprivation leads to fatigue, drowsiness while driving, and impaired alertness, directly leading to increased number of traffic accidents.

According to a chronic sleep restriction study by van Dongen et al. [27], test subjects who were limited to 6 hours of sleep for two weeks had neurobehavioral functioning similar to those who did not sleep at all for two days. Two studies by Lombardi et al. $[22,23]$ on sleep duration and work-related injury used data from the US National Health Interview Survey to show a decrease in sleep duration (compared to a sleep duration of 7.00 to 7.99 hours) led to an increase in the risk of injury, with less than 5 hours having odds ratios up to 2.65 , and, in sleep duration categories greater than 8 hours, the elevated risk was marginally significant. In our study, the injury group reported lower mean sleep durations than the non-injury group. Although no significant differences were observed be- tween the 8 and 9 hours sleep group and the 7 hours reference group, the 10 hours sleep group had a significantly elevated risk. These results support prior research on sleep deprivation, although these findings were limited to the 10 hours sleep group a significant effect of increased sleep duration on injury was found.

There have been many sleep deprivation studies, but research on the effects of an increase in sleep duration has only recently received attention. A study by Faubel et al. [28] reported that an increase in sleep duration led to impaired cognitive function even when controlling other factors, such as obesity, health-related quality of life, awaking from sleep, chronic disease, and pharmacological treatment. Grandner and Drummond [16] proposed sleep fragmentation, fatigue, immune function, photoperiodic abnormalities, lack of physiological challenge, depression, sleep apnea, heart disease, failing health, and other variables may serve as possible mechanisms for an increase in sleep duration. In this study, the quality of sleep was not examined; therefore the potential effects of sleep quality cannot be assessed. However, it is significant to find direct associations between an increase in sleep duration and injury while controlling for other variables that may affect an increase in sleep duration, such as underlying disease (hypertension, diabetes mellitus, arthritis, or depression), age, sex, occupation, region, current smoking status, alcohol consumption, and BMI. Biological factors associated with the effect of sleep duration on cognitive function have been reported by Kang et al. [29]; they found a relationship between the sleep-wake cycle and level of beta amyloid, which typically appears in Alzheimer's disease. In addition, Devore et al. [18], using 7 hours sleep duration as a reference, showed that beta amyloid 42/40 ratios had a U-shaped distribution. A drop in the beta amyloid ratio may eventually lead to Alzheimer's disease. Research on biological factors has centered on Alzheimer's disease and more studies of biological factors with a larger scope are necessary. The relationship between injury and cognitive function also requires further investigation.

Of the variables used as controls, young age, the occupational high injury risk group, uneducated and elementary educational level, smoking, and patients diagnosed with diabetes mellitus, arthritis, or depression all had a significantly elevated risk of injury. Previous research conducted in Korea [26,30] identified young age, smoking, drinking, occupation, low educational level, hypertension, diabetes mellitus, liver disease, mental illness, dementia, Parkinson's disease, epilepsy, work- 
ing hours, and working type as injury risk factors. The results from this study support such findings. In this study, alcohol abuse and dependence and those diagnosed with depression were the individual subgroups with a high risk for injury. In these subgroups, the primary preventive emphasis has been on intentional injury; our results suggest that the risk for unintentional injury should not be overlooked.

This study was based on the 2010 Community Health Survey. Some of the limitations of this survey include the crosssectional study design, which precludes the identification of causality, and the use of self-report materials. Studies by Lockley et al. [31] also mention these limitations. Unlike actual sleep duration, self-reports can be influenced by current conditions or psychological factors, leading to overestimation compared to objective measurements. Consequently, in this study, the association of sleep duration and injury could be influenced by psychological factors. To overcome these limitations, a study using objective measurements of sleep and the quality of sleep is necessary. To overcome the limitations of a cross-sectional study, a retrospective cohort study targeting participants with injury experience could be useful in establishing causality.

\section{CONFLICT OF INTEREST}

The authors have no conflicts of interest with the material presented in this paper.

\section{REFERENCES}

1. Hublin C, Kaprio J, Partinen M, Koskenvuo M. Insufficient sleep: a population-based study in adults. Sleep 2001;24(4):3 92-400.

2. Akerstedt T, Nilsson PM. Sleep as restitution: an introduction. J Intern Med 2003;254(1):6-12.

3. Ferrie JE, Shipley MJ, Cappuccio FP, Brunner E, Miller MA, Kumari $\mathrm{M}$, et al. A prospective study of change in sleep duration: associations with mortality in the Whitehall II cohort. Sleep 2007; 30(12):1659-1666.

4. Organisation for Economic Cooperation and Development. Society at a glance 2009: OECD social indicators; 2009 [cited 2014 May 13]. Available from: http://www.oecd-ilibrary.org/ social-issues-migration-health/society-at-a-glance-2009_ soc_glance-2008-en.

5. Gangwisch JE, Heymsfield SB, Boden-Albala B, Buijs RM, Kreier
F, Pickering TG, et al. Short sleep duration as a risk factor for hypertension: analyses of the first National Health and Nutrition Examination Survey. Hypertension 2006;47(5):833-839.

6. Yaggi HK, Araujo AB, McKinlay JB. Sleep duration as a risk factor for the development of type 2 diabetes. Diabetes Care 2006;29(3):657-661.

7. Ayas NT, White DP, Manson JE, Stampfer MJ, Speizer FE, Malhotra $A$, et al. A prospective study of sleep duration and coronary heart disease in women. Arch Intern Med 2003;163(2): 205-209.

8. Marshall NS, Glozier N, Grunstein RR. Is sleep duration related to obesity? A critical review of the epidemiological evidence. Sleep Med Rev 2008;12(4):289-298.

9. Lee JW, Lee NS, Lee KJ, Kim JJ. The association between hypertension and lifestyle in express bus drivers. Korean J Occup Environ Med 2011;23(3):270-278 (Korean).

10. Ock SM, Ju SY, Choi WS, Park HM, Jung KI, Song CJ. Association of sleep hours with obesity in adult women. Korean J Obes 2008;17(3):110-116 (Korean).

11. Park YJ, Lee WC, Yim HW, Park YM. The Association between sleep and obesity in Korean adults. J Prev Med Public Health 2007;40(6):454-460 (Korean).

12. Youngstedt SD, Kripke DF. Long sleep and mortality: rationale for sleep restriction. Sleep Med Rev 2004;8(3):159-174.

13. Hublin C, Partinen M, Koskenvuo M, Kaprio J. Sleep and mortality: a population-based 22-year follow-up study. Sleep 2007;30(10):1245-1253.

14. Gallicchio L, Kalesan B. Sleep duration and mortality: a systematic review and meta-analysis. J Sleep Res 2009;18(2):148158.

15. Stamatakis KA, Punjabi NM. Long sleep duration: a risk to health or a marker of risk? Sleep Med Rev 2007;11(5):337-339.

16. Grandner MA, Drummond SP. Who are the long sleepers? Towards an understanding of the mortality relationship. Sleep Med Rev 2007;11(5):341-360.

17. Durmer JS, Dinges DF. Neurocognitive consequences of sleep deprivation. Semin Neurol 2005;25(1):117-129.

18. Devore E, Grodstein F, Schernhammer E. Sleep duration and cognitive function: the nurses' health study. Alzheimers Dement 2012;8(4 Suppl):233.

19. Kim HJ, Kim JH, Park KD, Choi KG, Lee HW. A survey of sleep deprivation patterns and their effects on cognitive functions of residents and interns in Korea. Sleep Med 2011;12:390-396.

20. Statistics Korea. Cause of death statistics 2012. Daejeon: Statistics Korea; 2012, p. 48-52 (Korean). 
21. Youn KW, Lee SY, Yim SH. Human factors involved in traffic accidents and unsafe driving behaviors of taxi drivers. Korean J Occup Environ Med 2006;18(4):307-317 (Korean).

22. Lombardi DA, Folkard S, Willetts JL, Smith GS. Daily sleep, weekly working hours, and risk of work-related injury: US National Health Interview Survey (2004-2008). Chronobiol Int 2010;27(5):1013-1030.

23. Lombardi DA, Wirtz A, Willetts JL, Folkard S. Independent effects of sleep duration and body mass index on the risk of a work-related injury: evidence from the US National Health Interview Survey (2004-2010). Chronobiol Int 2012;29(5):556564.

24. Kim JS, Oh MK, Park BK, Lee MK, Kim GJ. Screening criteria of alcoholism by alcohol use disorders identification test (AUDIT) in Korea. J Korean Acad Fam Med 1999;20(9):1152-1159 (Korean).

25. Kim KH, Lee KH, Lee SM, Lee SY, Lee YS, Lim KR, et al. The proportional mortality ratios of specific-cause mortality by occupation and education among men aged 20-64 in Korea (19932004). J Prev Med Public Health 2007;40(1):7-15 (Korean).

26. Jung DY, Kim HC, Leem JH, Park SG, Lee DH, Lee SJ, et al. Estimated occupational injury rate and work related factors based on data from the fourth Korea national health and nutrition examination survey. Korean J Occup Environ Med 2011; 23(2):149163 (Korean).

27. Van Dongen HP, Maislin G, Mullington JM, Dinges DF. The cumulative cost of additional wakefulness: dose-response effects on neurobehavioral functions and sleep physiology from chronic sleep restriction and total sleep deprivation. Sleep 2003; 26(2):117-126.

28. Faubel R, Lopez-Garcia E, Guallar-Castillon P, Graciani A, Banegas JR, Rodriguez-Artalejo F. Usual sleep duration and cognitive function in older adults in Spain. J Sleep Res 2009; 18(4):427435.

29. Kang JE, Lim MM, Bateman RJ, Lee JJ, Smyth LP, Cirrito JR, et al. Amyloid-beta dynamics are regulated by orexin and the sleep-wake cycle. Science 2009;326(5955):1005-1007.

30. Ko JW, Kim WJ, Kang YJ, Park JO, Park KH, Lee EJ. Risk factors of injured patients with frequent emergency department visits: a single center study in Jeju island. J Korean Soc Emerg Med 2012;23(3):327-333 (Korean).

31. Lockley SW, Skene DJ, Arendt J. Comparison between subjective and actigraphic measurement of sleep and sleep rhythms. J Sleep Res 1999;8(3):175-183. 